\title{
Airways inflammation and treatment during acute exacerbations of COPD
}

\author{
Erik Bathoorn' \\ Huib Kerstjens' \\ Dirkje Postma' \\ Wim Timens ${ }^{2}$ \\ William MacNee ${ }^{3}$ \\ 'Groningen Research Institute \\ for Asthma and COPD (GRIAC), \\ Department of Pulmonology, \\ ${ }^{2}$ Department of Pathology, University \\ Medical Center Groningen, University \\ of Groningen, the Netherlands; \\ ${ }^{3}$ Edinburgh Lung and the Environment \\ Group Initiative/Colt Research \\ Laboratories, Medical School, \\ University of Edinburgh, Edinburgh, \\ Scotland, United Kingdom
}

\begin{abstract}
Introduction: Inflammation is a core feature of acute chronic obstructive pulmonary disease (COPD) exacerbations. It is important to focus on inflammation since it gives insight into the pathological changes causing an exacerbation, thereby possibly providing directions for future therapies which modify inflammation.

Objectives: To provide a cell-by-cell overview of the inflammatory processes during COPD exacerbations. To evaluate cell activation, and cytokine production, cellular interactions, damaging effects of inflammatory mediators to tissue, and the relation to symptoms at the onset of COPD exacerbations. To speculate on future therapeutic options to modify inflammation during COPD exacerbations.

Results: During COPD exacerbations, there is increased airway wall inflammation, with pathophysiological influx of eosinophils, neutrophils, and lymphocytes. Although links have been suggested between the increase in eosinophils and lymphocytes and a viral etiology of the exacerbation, and between the increase in neutrophils and a bacterial aetiology, these increases in both inflammatory cell types are not limited to the respective aetiologies and the underlying mechanisms remain elusive.
\end{abstract}

Conclusion: Further research is required to fully understand the inflammatory mechanisms in the onset and development of COPD exacerbations. This might make inflammatory pathway-specific intervention possible, resulting in a more effective treatment of COPD exacerbations with fewer side effects.

Keywords: COPD, exacerbation, inflammation, therapy

\section{Introduction}

Exacerbations are an important feature of chronic obstructive pulmonary disease (COPD) since they result in deterioration of a patient's quality of life (Seemungal et al 1998), contribute to decline in lung function (Donaldson et al 2002), and lead to over $50 \%$ of all COPD-related costs (Rutten-van Molken et al 1999; McGuire et al 2001). A disease state with such important consequences is in need of a tight definition, yet there is no consensus on such a definition. Several definitions have been proposed, focussing mostly on symptoms, sometimes in combination with infectious etiology (Madison and Irwin 1998; Davies et al 1999; Rodriguez-Roisin 2000). The most quoted definition is the one proposed by Anthonisen ie, a disease state characterized by an increase in symptoms of dyspnea, sputum volume and sputum purulence (Anthonisen et al 1987). Although many physicians consider an increase in inflammation as a core feature of an acute COPD exacerbation and indeed several studies provide evidence that this is the case, (see later in this review), none of the definitions in use for acute exacerbations capture the term inflammation. A first effort using inflammatory biomarkers to objectively confirm COPD exacerbations has been published recently. This study showed that plasma $\mathrm{C}$-reactive protein in combination with one major symptom 
is useful to confirm an exacerbation of COPD (Hurst et al 2006a). It is important to focus on inflammation, since it gives insight into the pathological changes causing an exacerbation, thereby possibly providing directions for future therapies which modify inflammation.

Bronchodilators and corticosteroids are the most commonly used drugs to treat exacerbations of COPD. Corticosteroids elicit a very broad array of anti-inflammatory actions. The use of systemic corticosteroids as treatment in COPD exacerbations is evidence-based (Wood-Baker et al 2005). The beneficial clinical effects have been extensively investigated, but less is known of the underlying anti-inflammatory effects of corticosteroids in exacerbations of COPD. In humans, only one placebo-controlled study (published in abstract form, see Bathoorn et al 2006) has investigated the anti-inflammatory mechanisms of steroids in COPD exacerbations, showing a suppressive effect of corticosteroids on sputum eosinophils.

It is difficult but certainly not impossible to study aspects of inflammation even during acute exacerbations of COPD. For instance, it has been shown that sputum can safely be induced also in patients with severe airflow limitation (Bhowmik et al 1998; Pizzichini et al 2002). Furthermore, techniques such as exhaled breath condensate can be applied but their repeatability is poor and it is uncertain which compartment (luminal, bronchial wall, alveolar, and parenchyma) the measured biomarkers reflect. More invasive assessment of inflammation in specific lung compartments by bronchial biopsy, broncho-alveolar lavage, and theoretically even transbronchial biopsy is severely restricted during acute exacerbations for obvious safety and ethical reasons. Evaluating autopsies of patients who died during COPD exacerbations would be very informative, but, to the best of our knowledge there are no reports of histopathology of lung tissue of patients deceased during COPD exacerbation.

The information on inflammation in COPD exacerbations is fragmentary so far, because mainly cross-sectional information has been obtained during exacerbations without information during the prior stable state and only occasionally information after the resolution of the exacerbation. Such information is necessary, since it will allow dissection of the predisposing factors, types of exacerbations, and patterns of resolution. The majority of information on inflammation during exacerbations in COPD is derived from studies using sputum inductions. Induced sputum is preferred to spontaneous sputum, since not all patients produce sputum spontaneously, and induced sputum contains higher percentage viable cells (Bhowmik et al 1998).
Many factors have to be taken into account when assessing inflammation in acute exacerbations of COPD, given the mixed etiology of these COPD exacerbations. The major causes of exacerbations which have been identified are viral and bacterial infection, and air pollution (Sunyer et al 1993; Fabbri and Hurd 2003). In approximately a third of all exacerbations a cause cannot be identified (White et al 2003). Certainly the different known causes of exacerbation will result in various types of inflammation (Papi et al 2006). Furthermore, concomitant use of medication such as inhaled or oral corticosteroids have to be taken into account, since they affect the type of inflammation (Barnes et al 2006).

The aim of the current review is to provide a cell-by-cell overview of the inflammatory processes during COPD exacerbations. We will evaluate cell numbers, activation, and cytokine production, cellular interactions, damaging effects of inflammatory mediators to tissue, and the relation to symptoms at the onset of COPD exacerbations. We also speculate on future therapeutic options to modify inflammation during COPD exacerbations.

\section{Inflammation \\ Neutrophils}

Neutrophil numbers are slightly, but significantly increased in bronchial glands, submucosa, and in subepithelial tissue in bronchial biopsies in stable COPD, compared with healthy persons (smokers or nonsmokers), and the numbers of neutrophils positively related to severity of the airflow limitation (Saetta et al 1997; Di Stefano et al 1998; Rutgers et al 2000). The latter might result from bacterial colonisation, which may be present in sputum in the case of severe airflow limitation (Banerjee et al 2004; Sethi et al 2006).

In COPD exacerbations, neutrophils are increased in both the submucosa and subepithelial tissue compared with the stable disease (Qiu et al 2003; Fujimoto et al 2005; Mercer et al 2005; Tsoumakidou et al 2005b; Bathoorn et al 2006; Papi et al 2006). The presence of potential pathogenic microorganisms in sputum in exacerbations is associated with higher neutrophil numbers (Gompertz et al 2001), as in stable disease. Exacerbations are associated with increased sputum neutrophil numbers and the change in neutrophil numbers correlate with greater decrease in forced expiratory volume in one second $\left(\mathrm{FEV}_{1}\right)$ during exacerbations (Papi et al 2006; Wilkinson et al 2006) (Figure 1). At the time of the resolution of exacerbations, a decrease in neutrophil number is associated with eradication of bacteria from sputum (White et al 2003). A postulated underlying mechanism for this neutrophilia is the interaction of bacteria with Toll-like receptors on antigen presenting cells 


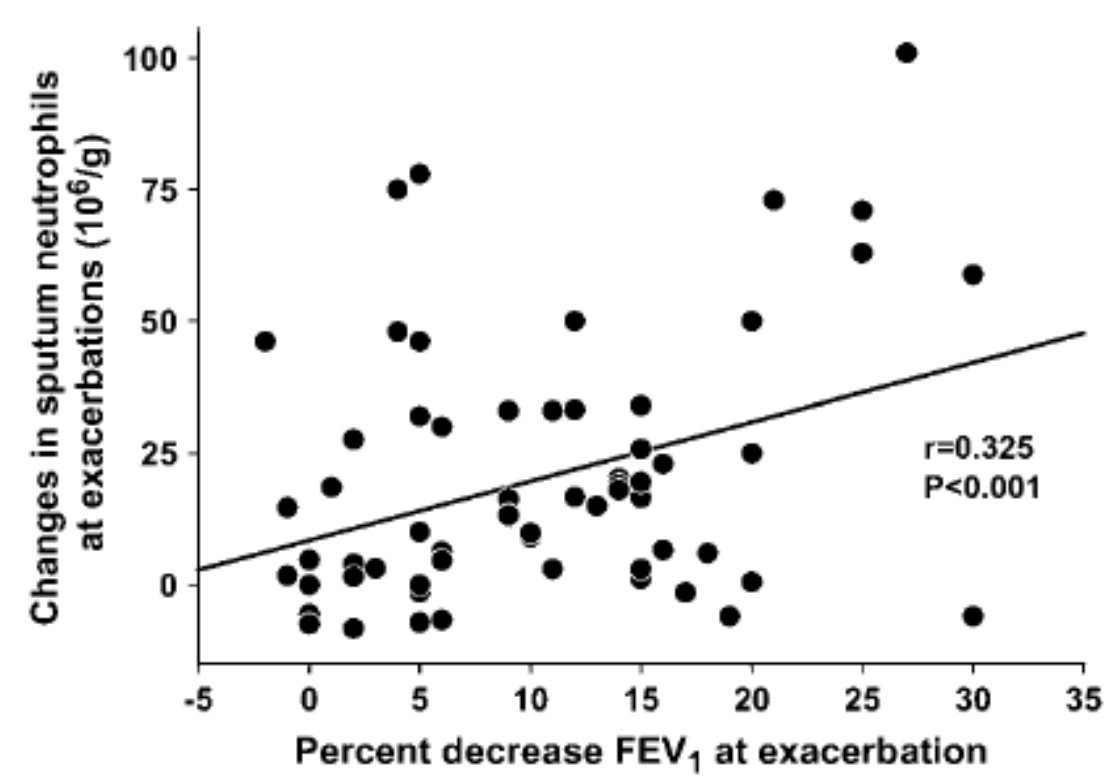

Figure I An increase in neutrophils concurs with a drop in FEV, during a COPD exacerbation. Data of 64 patients. Copyright $@ 2006$. Reproduced with permission from from Papi A, Bellettato CM, Braccioni F et al 2006. Infections and airway inflammation in chronic obstructive pulmonary disease severe exacerbations. Am J Respir Crit Care Med, I73:III4-2I.

Abbreviations: COPD, chronic obstructive pulmonary disease; $\mathrm{FEV}_{1}$, forced expiratory volume in one second.

and epithelial cells by bacteria, which induces the release of pro-inflammatory cytokines, as with viral infections (Wetzler 2003; Ritter et al 2005). Although neutrophils show a relation with the presence of bacteria in both stable COPD and exacerbations, the increase in neutrophils is not limited to bacterial exacerbations: neutrophils have been shown to increase also during exacerbations associated with viral infections and in those without demonstrable pathogens (Papi et al 2006).

The most potent chemoattractants of neutrophils are leukotriene B4, interleukin-8 (IL-8), epithelial-derived neutrophil attractant-78, and tumor necrosis factor- $\alpha$ (TNF- $\alpha$ ) (Saetta et al 1994; Bathoorn et al 2005; Fujimoto et al 2005; Mercer et al 2005; Papi et al 2006). COPD patients with frequent exacerbations have higher IL-8 levels in sputum in the stable phase compared to patients with infrequent exacerbations, illustrating the important role of neutrophil chemoattraction in the pathophysiology of COPD exacerbations (Tumkaya et al 2007). The recruitment of neutrophils is facilitated by increased expression of adhesion molecules on the surface of circulating neutrophils, which are stress-inducible and up-regulated during COPD exacerbations (Albelda 1991; Selby et al 1991; Noguera et al 1998). Leukotrienes are also very potent chemoattractants of inflammatory cells during COPD exacerbations. Not only leukotriene B4, but also leukotriene E4 is increased during exacerbations and related to blood oxygen tension and airway obstruction in the course of exacerbations (Shindo et al 1997; Gompertz et al 2001; Biernacki et al 2003).
One of the main functions of neutrophils is their antibacterial role. To kill bacteria, neutrophils degranulate, releasing myeloperoxidase, a highly reactive acidic oxidant (Furtmuller et al 2000), which is increased during COPD exacerbations, both in sputum and serum (Aaron et al 2001).

Chronic obstructive pulmonary disease exacerbations caused by bacterial infections resulting in increased sputum neutrophils, often evoke a systemic inflammatory response: inflammatory markers such as circulating neutrophil numbers, C-reactive protein, fibrinogen, and serum IL-6 are increased during exacerbations (Wedzicha et al 2000; Hurst et al 2006a, 2006b). Several mechanisms have been proposed for the origin of the increased systemic inflammation. These include:1) spill over of inflammatory mediators from the pulmonary compartment; 2) an inflammatory reaction to tissue hypoxia; 3 ) a reaction induced by the pro-inflammatory bacterial product lipopolysaccharide (Wouters 2005).

Systemic inflammation could be important in the follow-up of exacerbations, since COPD patients with frequent exacerbations have a smaller reduction of systemic inflammatory markers in the recovery of an exacerbation, and nonrecovery of an exacerbation is related to persistently increased systemic inflammation (Perera et al 2007). Furthermore, systemic inflammation during COPD exacerbations may induce cardiovascular co-morbidity, by causing hemostasis and thrombosis. However, a relationship between increased inflammation caused by infections during exacerbations and 
the risk for cardiovascular heart disease has yet not been proven (Wedzicha et al 2000; Rothenbacher et al 2003; MacCallum 2005).

In conclusion, neutrophils are predominantly increased in more severe exacerbations caused by bacterial infections, however this increase is not limited to bacteria-associated exacerbations alone.

\section{Eosinophils}

Eosinophilic inflammation is generally not associated with COPD. In a stable phase, there is little evidence for a role of eosinophils except in a specific COPD phenotype, which shows little emphysema and bronchial wall thickening on computed tomography scans and a good response to corticosteroids (Pizzichini et al 1998; Fujimoto et al 1999; Brightling et al 2001, 2005; Kitaguchi et al 2006). This COPD phenotype has many features of asthma, and it would be of interest to compare in airway tissue histology from patients with this particular COPD phenotype and that of asthma patients. During COPD exacerbations it is recognised that an "asthma-like" inflammatory pattern in the airways may exist with increased numbers of eosinophils (Barnes 2000). At least 5 studies have found this in mild to moderate COPD exacerbations in airway wall biopsies, and by broncho-alveolar lavage and sputum induction, although some of these studies also included patients with chronic bronchitis without airway obstruction (17; 19; 27-29) (Figure 2). The increase in eosinophils during exacerbations shown in Figure 2 suggests that there is a subset of patients in which airway eosinophilia increases. The increase in eosinophils during COPD exacerbations is at least partially related to viral infections (Papi et al 2000; Rohde et al 2004).
Pathogens are recognized by Toll-like receptors on epithelial cells, which induce the release of several pro-inflammatory cytokines (Hewson et al 2005; Ritter et al 2005). The eosinophil attracting chemokines "Regulated upon Activation, Normal T-cell Expressed, and Secreted" (RANTES), eotaxin, and interleukin-5 (IL-5) have been reported to be increased during COPD exacerbations (Zhu et al 2001; Bocchino et al 2002; Rohde et al 2004; Fujimoto et al 2005).

Although, as documented above, the eosinophil has been consistently shown to be associated with COPD exacerbations, many clinicians do not intuitively consider this a relevant cell to target in the treatment of exacerbations. It is interesting, however, to realise that the eosinophil is the most steroid sensitive cell in the airways and that much of what is achieved with corticosteroids during exacerbations may be related to effects of steroids on eosinophils (Davies et al 1999; Niewoehner et al 1999). In stable COPD, it has been shown that higher number of eosinophils correlate with responsiveness to both oral and inhaled corticosteroids (Fujimoto et al 1999; Brightling et al 2000, 2005). Additionally, it has been shown recently that both prednisolone and the combination of inhaled budesonide plus formoterol suppress sputum eosinophilia during COPD exacerbations (Bathoorn et al 2006).

Whether this steroid-induced decrease in eosinophils has clinical benefit has not directly been proven. However, a decrease of soluble interleukin-5 receptor alpha in the resolution phase of a virus-induced exacerbation has been related to an increase in $\mathrm{FEV}_{1}$, suggesting that such a relationship may exist (Rohdeet al 2004).

Not only the eosinophils themselves, but also their products such as eosinophil cationic protein are increased in sputum and in serum during COPD exacerbations (Fiorini et al
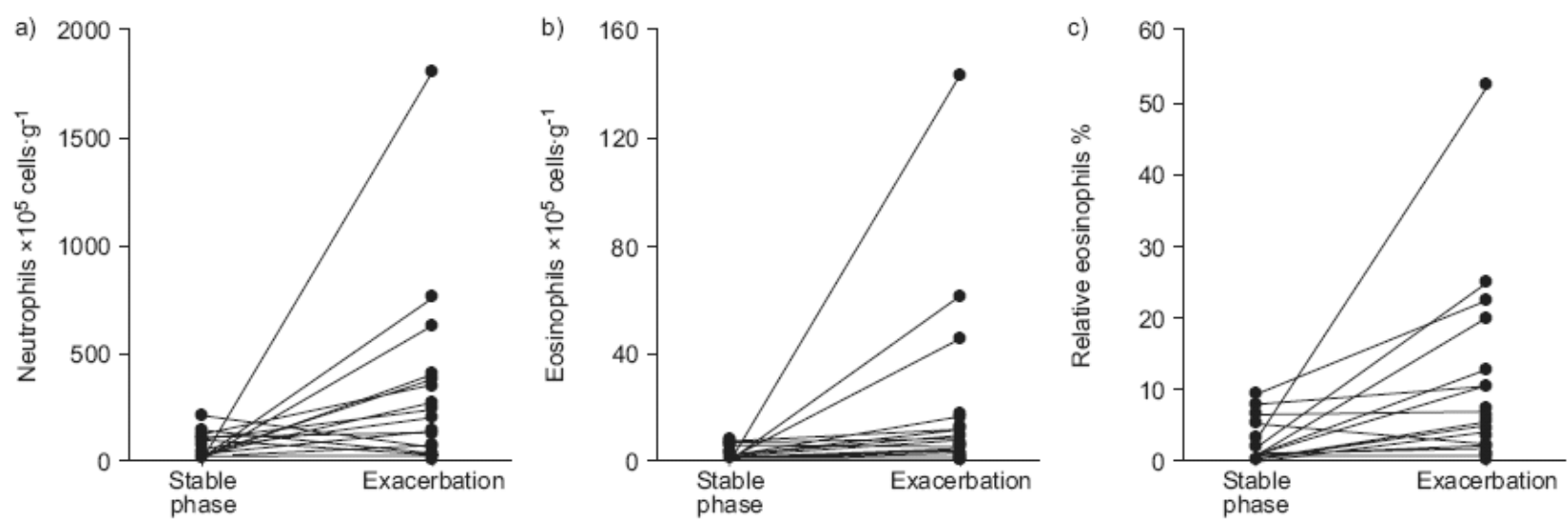

Figure 2 Changes in sputum eosinophil numbers from stable phase of COPD to the onset of an exacerbation. Copyright $@ 2005$. Reproduced with permission Fujimoto K, Yasuo M, Urushibata K et al 2005. Airway inflammation during stable and acutely exacerbated chronic obstructive pulmonary disease. Eur Respir J, 25:640-6. Abbreviation: COPD, chronic obstructive pulmonary disease. 
2000; Fujimoto et al 2005). Eosinophil cationic protein among other effects causes tissue damage and tissue remodelling in in vitro studies (Zagai et al 2004). This could explain at least part of the association between exacerbation frequency and excess decline in lung function (Donaldson et al 2002).

\section{Lymphocytes}

\section{Stable disease}

Lymphocytes are thought to play an important role in the development and progression of COPD. Particularly CD8+ lymphocytes have been intensively investigated. CD8+ cells are increased in the airway submucosa and in peripheral blood in patients with stable COPD, and the number of CD8+ cells is positively related to the severity of airflow limitation (de Jong et al 1997; O'Shaughnessy et al 1997; Roland et al 2001). Most CD8+ cells are supposed to represent cytotoxic memory cells, which are produced after a first airway infection, and facilitate a faster and more effective response of the immune system when the next infection occurs. Indeed, in vivo studies show that more effective airway viral clearance is associated with higher CD8+ cell numbers. $\mathrm{CD} 8+$ cell numbers in the airways remain high for several months after viral infections, and stabilize after 6 months (Hou et al 1992; Liang et al 1994; Hogan et al 2001). The higher CD8+ numbers in stable COPD patients may be caused by the occurrence of an airway infection in the preceding few months, or alternatively there is a continuous low grade infection and the numbers of CD8+ cells reflect the need to protect the lung tissue (Matsuse et al 1992; Retamales et al 2001; Woodland and Scott 2005). CD4+ cells, the helper T cells which produce pro-inflammatory cytokines, have also been reported to be increased in the peripheral blood of patients with COPD, particularly the interferon gamma producing cells (Majori et al 1999).

Several recent studies have also shown that B-cells are increased in bronchiolar and bronchial walls in the stable phase of COPD (Hogg et al 2004; Gosman et al 2006; van der Strate et al 2006). B-cells play a role in the humeral immune response, producing antibodies to antigens. The pathological role of the increased B-cells in COPD is still uncertain. It has been speculated that viral airway infections may underlie the rise in B-cells (Gerhard et al 1997; Coro et al 2006), but an autoimmune response, perhaps in reaction to cigarette smoke components or extracellular matrix products has also been postulated (Majo et al 2001; Agusti et al 2003; van der Strate et al 2006).

\section{Exacerbations}

During exacerbations lymphocytes in both induced sputum and tissue biopsies increase even further (Saetta et al 1994;
Fujimoto et al 2005; Mercer et al 2005; Bathoorn et al 2006) (Figure 3). This could partly be explained by the role of lymphocytes in the clearance of viruses. Despite consistent reports of the involvement of lymphocytes in COPD exacerbations, little data has been published on the lymphocyte subpopulations which are involved. In a small study, a CD8 type 2 mediated immune reaction occurred during COPD exacerbations (Tsoumakidou et al 2005a). To the best of our knowledge, no information on B-cells in COPD exacerbations has been published. We have no real insight on whether the changes in lymphocytes during exacerbations are a normal appropriate, an insufficient, or even an inappropriate or excessive response. If the response is insufficient, higher levels of specific lymphocytes may be more protective. Vaccination might be an intervention to increase the levels of specific lymphocytes. To explore whether vaccinations could be an effective intervention to prevent COPD exacerbations, more insight on the role of the lymphocyte and their subpopulations is needed. A large observational trial aiming to assess the role of T-cells in COPD exacerbations, which has started recruiting, will hopefully provide more information on this topic (ClinicalTrials.gov Identifier: NCT00281229).

In summary, airway infections are a common cause of COPD exacerbations, and as lymphocytes are the regulatory cells of immune response to infections, they could very well be key-players in the increased inflammation in both stable COPD and in the onset of COPD exacerbations, but the exact mechanisms by which the influx of cells is generated, their activation state, and their resulting effects still need to be elucidated.

\section{Macrophages}

Smokers with stable COPD have increased numbers of macrophages in airway tissue compared with chronic bronchitic patients without airflow limitation, or healthy controls (O’Shaughnessy et al 1997). The increase in macrophages is induced by smoking, since cessation of smoking in asymptomatic persons results in a decrease in sputum macrophages, and current smoking is positively related to macrophage numbers in airway submucosa and tissue (Willemse et al 2005a, 2005b).

During exacerbations of COPD, large observational studies have not shown a significant increase in sputum or airway tissue macrophages, neither as a percentage of total cells nor as an increase in absolute cell counts (Saetta et al 1994; Bhowmik et al 2000; Fujimoto et al 2005; Papi et al 2006). One study has even shown a significant decrease in sputum macrophages as percentage (Tsoumakidou et al 2005a). 


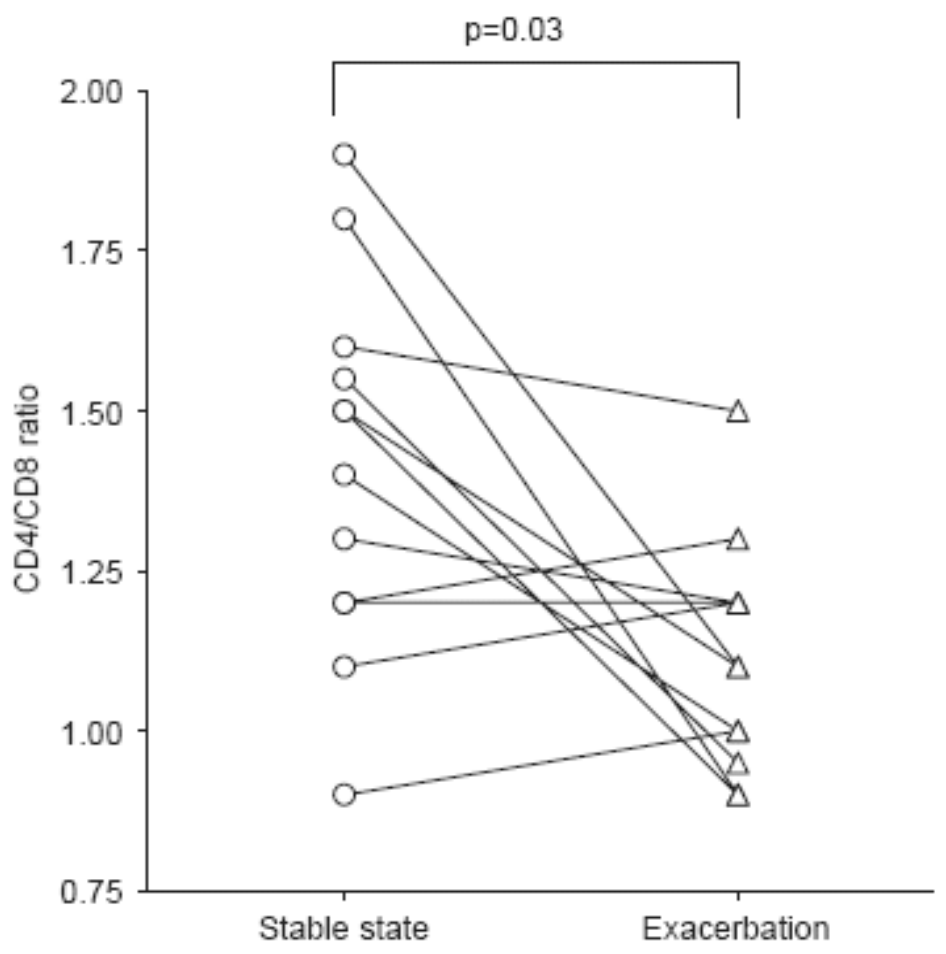

Figure 3 Lymphocytes are involved in the onset of COPD exacerbations. CD8+ cells are increased at COPD exacerbations, causing a decreased CD4/CD8 ratio. Copyright (C) 2005. Reproduced with permission from Tsoumakidou M,Tzanakis N, Chrysofakis G et al 2005a. Changes in sputum T-lymphocyte subpopulations at the onset of severe exacerbations of chronic obstructive pulmonary disease. Respir Med, 99:572-9.

Abbreviation: COPD, chronic obstructive pulmonary disease.

However, it is perhaps too early to conclude that macrophages are not involved during exacerbations. Since macrophages are responsive to cigarette smoke, a reduction in the number of cigarettes smoked during exacerbations could perhaps mask an increase in macrophages compared to the stable phase of disease. Future studies analyzing the inflammatory changes for nonsmokers separately could perhaps give a more definitive answer whether macrophages are increased during COPD exacerbation.

\section{Air pollution}

Epidemiological studies have shown that air pollution, particularly with fine particulate matters, can cause of COPD exacerbations (Sunyer et al 1993; Seaton et al 1995). Air pollution is associated with increased inflammation in the airways of elderly people, as they have higher exhaled nitric oxide levels when airway pollution increases (Adamkiewicz et al 2004). There is a lack of data on cellular airway inflammation caused by airway pollution induced COPD exacerbations, probably since it is difficult to identify these exacerbations caused by air pollution singularly, and since air pollution also interacts with viruses, resulting in a mixed origin of the exacerbation (Gilmour et al 2001).

\section{Oxidative stress}

Oxidative stress is an imbalance between the amount of oxidants and the capacity of antioxidants to scavenge these radicals. This imbalance originates from either an increased load of oxidants (reactive oxygen and nitrogen species and free radicals) and/or by a decreased antioxidant capacity. The increase in oxidants may result from release from inflammatory cells, or caused by increased inhalation of oxidants in cigarette smoke or polluted air (Church and Pryor 1985; Morrison et al 1999; Becker et al 2002). Oxidative stress induces Nuclear Factor- $\kappa \mathrm{B}$, a transcription factor involved in upregulating genes of many pro-inflammatory cytokines, resulting in increased inflammation (Rahman and MacNee 1998). Thus, inflammation induces oxidative stress and oxidative stress in turn causes increased inflammation.

Furthermore, the oxidative stress can be caused by a decreased antioxidant capacity. Theoretically, a decreased antioxidant capacity might result from poor nutritional status, however reports on the effect of food intake on the antioxidant capacity is conflicting (Cao et al 1998; Record et al 2001). However, an increased oxidant burden may lead to depletion of antioxidants in epithelial lining fluid in exacerbations of COPD (98). Another possibility could be 
a dysfunction of antioxidant producing enzymes (Yamada et al 2000; Hersh et al 2005).

During exacerbations, the antioxidant capacity is decreased, both in blood and in the airway submucosa (Rahman et al 1997; Drost et al 2005). This decrease in antioxidant capacity is probably caused by an increased requirement for the scavenging of oxidants, since hydroxygenperoxidase and 8-isoprostane, both products of reactions with oxygen radicals, are increased during COPD exacerbations in exhaled breath condensate (Biernacki et al 2003; Gerritsen et al 2005; Oudijk et al 2006).

Thus, oxidative stress is involved in COPD exacerbations, since there is an increased load of oxidants and the antioxidant capacity is decreased. It cannot be determined whether oxidative stress is a pathogenic cause of exacerbations, or a consequence of increased inhalation of oxidants, or infection with an increased inflammation.

\section{Anti-inflammatory therapies}

Modification of inflammation during COPD exacerbations is not without potential risks, since inflammatory cells play a role in defence against pathogens. Ideally any modification should improve symptoms and inflammatory damage, without increasing the risk of consequent infections. In vivo models of COPD exacerbations would be useful to test new anti-inflammatory drugs. Unfortunately, successful in vivo models for COPD exacerbations have not yet been reported as far as we know.

The only proven successful inflammation modifying therapy for COPD exacerbations thus far is treatment with corticosteroids. Treatment of COPD exacerbations with systemic corticosteroids improves lung function and oxygenation, reduces treatment failures, and shortens the length of hospital stay (Thompson et al 1996; Davies et al 1999; Niewoehner et al 1999; Maltais et al 2002). These beneficial effects are evidence based, however the magnitude of effect is modest. Lung function improves in the first 72 hours of treatment, but the improvement is not significantly different compared to placebo treatment after 2 weeks suggesting a spontaneous recovery in many patients. The reduction in length of hospitalisation with systemic steroids is 1-2 days (Davies et al 1999; Niewoehner et al 1999; Maltais et al 2002). However, these gains with steroid treatment come at a price. Treatment with systemic corticosteroids results in adverse systemic effects, such as hyperglycaemia, insomnia, and weight gain (Davies et al 1999; Maltais et al 2002; Aaron et al 2003). It has been calculated that one extra adverse effect occurs for every 6 patients treated with systemic corticosteroids (Wood-Baker et al 2005).
To avoid systemic adverse effect of oral steroids, treatment with inhaled steroids at an increased dose compared to the maintenance dose might be an option. Indeed, in one study treatment of COPD exacerbations with inhaled steroids improved lung function compared to placebo treatment, and caused less systemic effects than systemic steroid treatment (Maltais et al 2002). Since maximal bronchodilation and steroids are the current standard treatment of COPD exacerbations, combined long-acting bronchodilators, and inhaled steroids is a logical next intervention. A single study has investigated treatment of COPD exacerbations with combined budesonide and formoterol, which resulted in a decrease in sputum eosinophils, and an improvement of symptoms and health status (Bathoorn et al 2006). A larger study powered to document improvement in airflow limitation is under way and investigates whether this combined therapy is as effective as systemic steroids in the treatment of COPD exacerbations (ClinicalTrials.gov Identifier: NCT00259779).

The data on inflammation that observational studies of COPD exacerbations have provided, can potentially lead to development of novel inflammation modifying drugs. Some of these drugs have already been tested in the stable phase of COPD, and could be beneficial in the treatment of exacerbations.

Modification of inflammation by leukotriene antagonists has been tested in the treatment of stable COPD (Barnes 1989; Celik et al 2005). Both treatment of stable COPD patients with montelukast, a leukotriene receptor antagonist, and with BAYx1005 a leukotriene synthesis inhibitor resulted in a reduction in neutrophil numbers in sputum. Leukotriene B4 has been shown to be involved in the chemoattraction of neutrophils during exacerbations (Biernacki et al 2003). Therefore, treatment to reduce leukotriene levels might also be beneficial in COPD exacerbations.

Phosphodiesterase (PDE)-4 inhibition is an antiinflammatory mechanism that inhibits the break down of cyclic adenosine monophosphate in inflammatory cells (Barnette 1999). This results in higher intracellular cyclic adenosine monophosphate, which inactivates pro-inflammatory transcription factors by protein kinase A. Trials in patients with stable COPD showed improvements in lung function, quality of life, and exacerbation rates with this treatment (Rabe et al 2005; Rennard et al 2006). A reduction of bronchial wall CD8+ cells and macrophages has been demonstrated in stable disease, but the effect was rather small (Gamble et al 2003; Kerstjens and Timens 2003). PDE-4 inhibitors have not been tested in the treatment of COPD exacerbations. 
Table I Studies reporting increased airway neutrophils during exacerbations compared with stable phase

\begin{tabular}{|c|c|c|c|c|c|}
\hline Study & $\begin{array}{l}\text { Number of patients } \\
\text { in stable phasel } \\
\text { exacerbation }\end{array}$ & $\begin{array}{l}\text { FEV }, \% \text { of predicted } \\
\text { in stable phasel } \\
\text { exacerbation }\end{array}$ & $\begin{array}{l}\text { Number of sputum } \\
\text { neutrophils in stable } \\
\text { phase/exacerbation }\end{array}$ & $\begin{array}{l}\text { \% sputum neutrophils } \\
\text { in stable phase/ } \\
\text { exacerbation }\end{array}$ & Method \\
\hline Papi et al 2006 & $64 / 64$ & $49.5 / 39.4$ & $9.5 / 26.7 \times 10^{6} / \mathrm{gram}^{\mathrm{a}}$ & $\mathrm{nr}$ & Sputum induction \\
\hline Tsoumakidou 2005 & $12 / 12$ & $40 / \mathrm{nr}$ & $\mathrm{nr}$ & $83.5 / 98.0^{\mathrm{a}}$ & Sputum induction \\
\hline Bathoorn et al 2006 & $39 / 39$ & $61 / 51$ & $3.2 / 7 . I \times 10^{6} / \mathrm{mL}^{\mathrm{a}}$ & $72.5 / 72.0$ & Sputum induction \\
\hline Mercer et al 2005 & $19 / 12$ & $\mathrm{nr} / 37.6$ & $1.48 / 2.19 \times 10^{6} / \mathrm{gram}^{\mathrm{a}}$ & $80.0 / 87.5$ & Sputum induction \\
\hline Fujimoto et al 2005 & $30 / 30$ & $52.9 / 40.6$ & $4.4 / 24.4 \times 10^{6} / \mathrm{gram}^{\mathrm{a}}$ & $83.4 / 81.7$ & Sputum induction \\
\hline Balbi et al 1997 & $8 / 5$ & $71 / 64$ & $10 / 83 \times 10^{3} / \mathrm{mL}^{\mathrm{a}}$ & $\mathrm{nr} / \mathrm{nr}$ & BAL \\
\hline
\end{tabular}

Notes: ${ }^{\mathrm{p}} \mathrm{p}<0.05$; nr, data not reported.

Tumor necrosis factor- $\alpha$ is a general pro-inflammatory cytokine, and its levels are increased in sputum at the onset of COPD exacerbations (Aaron et al 2001). Inhibition of TNF- $\alpha$ could lead to a reduction in inflammation during COPD exacerbations. Systemic anti-TNF- $\alpha$ administration has been tested in 22 patients with mild-to moderate COPD, yet in a stable phase of disease (van der Vaart et al 2005). This study showed no positive effects. Perhaps more severe COPD, or more specifically COPD exacerbations, would be an appropriate indication for anti-TNF- $\alpha$ treatment.

Inhibition of cytokines involved in the recruitment of eosinophils, such as IL-5, RANTES, and eotaxin could also be a strategy to modify inflammation during COPD exacerbations. This has not been studied in COPD so far. In vitro studies and studies in patients with asthma show beneficial effects of such specific antieosinophil therapies, and perhaps these therapies should be tested as a treatment of COPD exacerbations (Elsner et al 1997; Heath et al 1997; Teixeira et al 1997; Proudfoot et al 1999; Leckie et al 2000; Chvatchko et al 2003; Flood-Page et al 2003; Kumar et al 2004; Tanaka et al 2004).

Another pathway to reduce inflammation is inhibition of the mitogen-activated protein (MAP)-kinase pathway. MAP-kinase pathways are involved in the signal transduction from an external inflammatory stimulus to an inflammatory response, by activating intracellular transcription factors for pro-inflammatory cytokine gene expression (Lee and
Goodbourn 2001). In vivo studies investigating MAP-kinase inhibitors show reducing effects on neutrophil inflammation in a lipopolysaccharide inhalation model, and on eosinophilic inflammation in an allergy model (Underwood et al 2000; Chapman et al 2001). The first generation MAP-kinase inhibitors had significant side effects in humans. A second generation is in development with fewer side effects (Adams et al 1998) and might be introduced in the treatment of airway inflammatory diseases in the near future, including COPD exacerbations.

Macrolides are well known for their antimicrobial activity. Besides their antimicrobial activity, macrolides have antiinflammatory effects. They reduce pro-inflammatory cytokine production, and neutrophilic and eosinophilic inflammation (Gotfried 2004). Part of these anti-inflammatory effects involve the extracellular regulated protein kinase pathway, a MAP-kinase pathway (Shinkai et al 2006). Macrolide treatment in stable COPD patients induced a reduction in neutrophilic inflammation without improvement in health status or exacerbation rate (Banerjee et al 2005; Parnham et al 2005). We did not find any reports on the effects of COPD exacerbations with macrolides compared to other antibiotics in relation to their anti-inflammatory properties.

Inhibition of MAP-kinase can also be established by inhalation of low dose carbon monoxide (CO) (Otterbein et al 2000). CO inhalation is usually associated with toxic

Table 2 Studies reporting increased airway eosinophils during exacerbations compared with stable phase

\begin{tabular}{|c|c|c|c|c|c|}
\hline Study & $\begin{array}{l}\text { Number of patients } \\
\text { in stable phase/ } \\
\text { exacerbation }\end{array}$ & $\begin{array}{l}\text { FEV, \% of predicted } \\
\text { in stable phasel } \\
\text { exacerbation }\end{array}$ & $\begin{array}{l}\text { Number of sputum } \\
\text { eosinophils in stable } \\
\text { phase/exacerbation }\end{array}$ & $\begin{array}{l}\% \text { sputum eosinophils } \\
\text { of in stable phasel } \\
\text { exacerbation }\end{array}$ & Method \\
\hline Fujimoto et al 2005 & $30 / 30$ & $52.9 / 40.6$ & $0.1 / 1.3 \times 10^{6} / \mathrm{gram}^{\mathrm{a}}$ & $1.7 / 6.7^{\mathrm{a}}$ & Sputum induction \\
\hline Bathoorn et al 2006 & $39 / 39$ & $61 / 51$ & $0.1 / 0.4 \times 10^{6} / \mathrm{mL}^{\mathrm{a}}$ & $2.7 / 2.8$ & Sputum induction \\
\hline Mercer et al 2005 & $19 / 12$ & $\mathrm{nr} / 37.6$ & $0.01 / 0.07 \times 10^{6} / \mathrm{gram}^{\mathrm{a}}$ & $0.75 / 1.0$ & Sputum induction \\
\hline Balbi et al 1997 & $8 / 5$ & $71 / 64$ & $1.9 / 6.7 \times 10^{3} / \mathrm{mL}^{\mathrm{a}}$ & $\mathrm{nr} / \mathrm{nr}^{\mathrm{a}}$ & BAL \\
\hline Papi et al 2006 & $\begin{array}{l}\text { 15//5 subgroup } \\
\text { viral exacerbations }\end{array}$ & $\mathrm{nr} / \mathrm{nr}$ & $0.9 / 3.5 \times 10^{6} / \mathrm{gram}^{\mathrm{a}}$ & $\mathrm{nr} / \mathrm{nr}$ & Sputum induction \\
\hline
\end{tabular}

Notes: ${ }^{\mathrm{p} p}<0.05$; nr, data not reported. 
Table 3 Studies reporting increased airway lymphocytes during exacerbations compared with stable phase

\begin{tabular}{|c|c|c|c|c|c|}
\hline Study & $\begin{array}{l}\text { Number of patients } \\
\text { in stable phasel } \\
\text { exacerbation }\end{array}$ & $\begin{array}{l}\text { FEV, \% of predicted } \\
\text { in stable phasel } \\
\text { exacerbation }\end{array}$ & $\begin{array}{l}\text { Number of sputum } \\
\text { lymphocytes in stable } \\
\text { phase/exacerbation }\end{array}$ & $\begin{array}{l}\text { \% sputum lymphocytes } \\
\text { in stable phasel } \\
\text { exacerbation }\end{array}$ & Method \\
\hline Fujimoto et al 2005 & $30 / 30$ & $52.9 / 40.6$ & $0.2 / 0.7 \times 10^{6} / \mathrm{gram}^{\mathrm{a}}$ & $4.0 / 4.9$ & Sputum induction \\
\hline Bathoorn et al 2006 & $39 / 39$ & $61 / 51$ & $0 / 0.1 \times 10^{6} / \mathrm{mL}^{\mathrm{a}}$ & $0.3 / 0.7^{\mathrm{a}}$ & Sputum induction \\
\hline Mercer et al 2005 & $19 / 12$ & $\mathrm{nr} / 37.6$ & $0.03 / 0.31 \times 10^{6} / \mathrm{gram}^{\mathrm{a}}$ & $2.5 / 4.5$ & Sputum induction \\
\hline Papi et al 2006 & $64 / 64$ & $49.5 / 39.4$ & $0.04 / 0.11 \times 10^{6} / \mathrm{gram}^{\mathrm{b}}$ & $\mathrm{nr}$ & Sputum induction \\
\hline
\end{tabular}

Notes: ${ }^{\mathrm{a}} \mathrm{p}<0.05 ;{ }^{\mathrm{b}} \mathrm{p}=0.06$; $\mathrm{nr}$, data not reported.

effects which occur during exposure to high doses or to long-term low levels. In contrast, exposure to low dose $\mathrm{CO}$ can be cytoprotective (Otterbein and Choi 2000), and both in vitro and in vivo studies have shown its anti-inflammatory effects on the airways (Chapman et al 2001; Ameredes et al
2003; Ning et al 2005). Inhalation of low dose CO in an ovalbumin-induced allergic in vivo model attenuates the eosinophilic inflammation by reducing IL-5 levels, and reduces bronchial hyperresponsiveness to methacholine (Figure 4). Therefore, $\mathrm{CO}$ has been postulated to have a potential
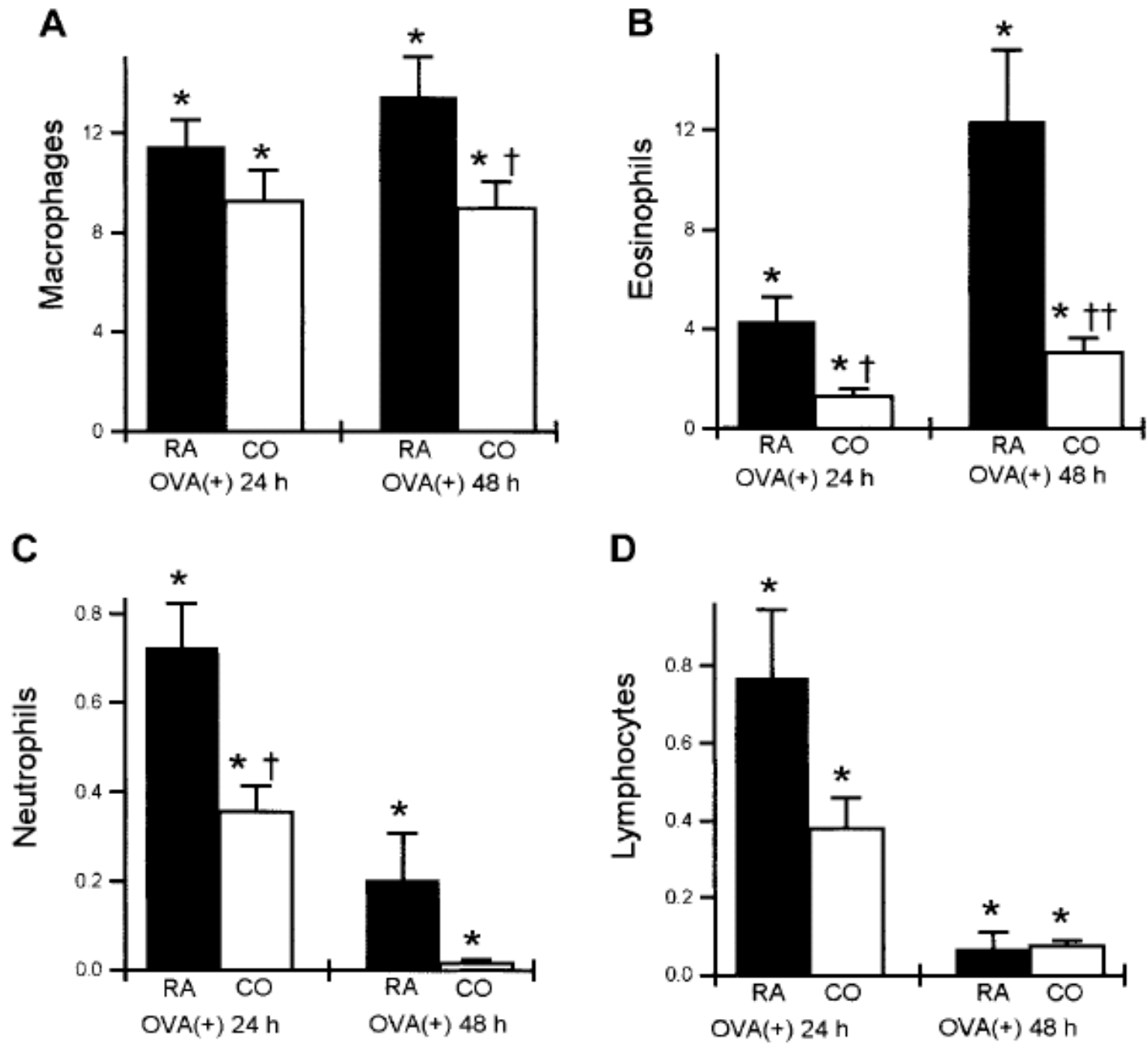

Figure $4 \mathrm{In}$ an aero-allergen induced allergic inflammation mice model, inhaled carbon monoxide (CO) reduced inflammatory cell counts $(\times 104 / \mathrm{mL})$ in broncho-alveolar lavage fluid. Treated animals (CO) received 250 parts per million inhaled carbon monoxide 2 hours before the aero-allergen challenge (OVA) and continuously thereafter. Control animals were kept in room air (RA) for the duration of the experiment. Copyright (C) 200I. Reproduced with permission from Chapman JT, Otterbein LE, Elias JA et al 200I. Carbon monoxide attenuates aeroallergen-induced inflammation in mice. Am J Physiol Lung Cell Mol Physiol, 28I:L209-L2I6.

Notes: *Significantly increased $(p<0.05)$ from sham-challenged animals; †Significantly different $(p<0.05)$ from mice kept in room air; $\nmid \nmid$ Significantly different $(p<0.0007)$ from mice kept in room air. 
therapeutic role in pulmonary medicine (Slebos et al 2003). The effects of inhaled $\mathrm{CO}$ have been tested in healthy volunteers, who were infused with lipopolysaccharide, but CO did not influence plasma TNF- $\alpha$, IL-6, and IL-8 levels, which were increased by lipopolysaccharide (Mayr et al 2005). Since the predominant effect of CO seems to be a reduction of eosinophils, asthma and COPD exacerbations could be more appropriate indications. The results of anti-inflammatory effects of inhaled $\mathrm{CO}$ on inflammatory airway diseases will appear in the near future (Bathoorn et al 2007).

\section{Conclusions}

During COPD exacerbations, there is increased airway wall inflammation, with pathophysiological influx of eosinophils, neutrophils, and lymphocytes. There are no reports of increased macrophages during COPD exacerbations. Although links have been suggested between the increase in eosinophils and lymphocytes and a viral etiology of the exacerbation, and between the increase in neutrophils and a bacterial etiology, these increases in both inflammatory cell types are not limited to the respective etiologies and the underlying mechanisms remain elusive. Reports on increases in lymphocytes during COPD exacerbations are consistent, and they might play a key role in the protection against recurrent infections, which evoke an inflammatory response. There is little data on the subtypes of lymphocytes involved in the onset of COPD exacerbations, which would be essential to dissect the normal from the pathophysiological immune response, which may be increased either excessively or insufficiently. Studies that document the onset of inflammatory changes in COPD exacerbations should prove useful to develop inflammation-modifying interventions.

The only successful inflammation-modifying drugs during exacerbations so far are corticosteroids, but their beneficial effects are modest and steroids do have important side effects. New data suggest that the use of inhaled steroids (in combination with long-acting bronchodilators) may be an alternative to systemic steroids in the treatment of exacerbations with less potential for systemic side effects. Whether this is as effective as systemic steroids needs to be assessed in future studies.

Several more specific cytokine or pathway inhibiting drugs are in development for stable COPD. A further step might be to test these drugs also in COPD exacerbations. However, it is also possible that new drugs that specifically target inflammatory changes pertinent to COPD exacerbations can be developed. In conclusion, further research is required to fully understand the inflammatory mechanisms in the onset and development of COPD exacerbations. This might make inflammatory pathway-specific intervention possible, resulting in a more effective treatment of COPD exacerbations with fewer side effects.

\section{References}

Aaron SD, Angel JB, Lunau M, et al. 2001. Granulocyte inflammatory markers and airway infection during acute exacerbation of chronic obstructive pulmonary disease. Am J Respir Crit Care Med, 163:349-55.

Aaron SD, Vandemheen KL, Hebert P, et al. 2003. Outpatient oral prednisone after emergency treatment of chronic obstructive pulmonary disease. N Engl J Med, 348:2618-25.

Adamkiewicz G, Ebelt S, Syring M, et al. 2004. Association between air pollution exposure and exhaled nitric oxide in an elderly population. Thorax, 59:204-9.

Adams JL, Boehm JC, Kassis S, et al. 1998. Pyrimidinylimidazole inhibitors of CSBP/p38 kinase demonstrating decreased inhibition of hepatic cytochrome P450 enzymes. Bioorg Med Chem Lett, 8:3111-16.

Agusti A, MacNee W, Donaldson K, et al. 2003. Hypothesis: does COPD have an autoimmune component? Thorax, 58:832-4.

Albelda SM. 1991. Endothelial and epithelial cell adhesion molecules. Am J Respir Cell Mol Biol, 4:195-203.

Ameredes BT, Otterbein LE, Kohut LK, et al. 2003. Low-dose carbon monoxide reduces airway hyperresponsiveness in mice. Am J Physiol Lung Cell Mol Physiol, 285:L1270-L1276.

Anthonisen NR, Manfreda J, Warren CP, et al. 1987. Antibiotic therapy in exacerbations of chronic obstructive pulmonary disease. Ann Intern Med, 106:196-204.

Balbi B, Bason C, Balleari E, et al. 1997. Increased bronchoalveolar granulocytes and granulocyte/macrophage colony-stimulating factor during exacerbations of chronic bronchitis. Eur Respir J, 10:846-50.

Banerjee D, Khair OA, Honeybourne D. 2004. Impact of sputum bacteria on airway inflammation and health status in clinical stable COPD. Eur Respir J, 23:685-91.

Banerjee D, Khair OA, Honeybourne D. 2005. The effect of oral clarithromycin on health status and sputum bacteriology in stable COPD. Respir Med, 99:208-15.

Barnes NC, Qiu YS, Pavord ID, et al. 2006. Antiinflammatory effects of salmeterol/fluticasone propionate in chronic obstructive lung disease. Am J Respir Crit Care Med, 173:736-43.

Barnes PJ. 1989. A new approach to the treatment of asthma. $N$ Engl $J$ Med, 321:1517-27.

Barnes PJ. 2000. Chronic obstructive pulmonary disease. $N$ Engl J Med, 343:269-80.

Barnette MS. 1999. Phosphodiesterase 4 (PDE4) inhibitors in asthma and chronic obstructive pulmonary disease (COPD). Prog Drug Res, 53:193-229.

Bathoorn E, Liesker JJW, Postma DS, et al. 2005. Change in inflammation during COPD exacerbations. Eur Respir J, 26(Suppl 49):15s.

Bathoorn E, Liesker JJW, Postma DS, et al. 2006. Anti-inflammatory effect of combined budesonide/formoterol treatment in COPD exacerbations. Proc Am Thor Soc, 2006.

Bathoorn E, Slebos DJ, Postma DS, et al. 2007. Anti-inflammatory effects of inhaled carbon monoxide in patients with COPD: a pilot study. Eur Respir J, 30:1131-7.

Becker S, Soukup JM, Gallagher JE. 2002. Differential particulate air pollution induced oxidant stress in human granulocytes, monocytes and alveolar macrophages. Toxicol In Vitro, 16: 209-18.

Bhowmik A, Seemungal TA, Sapsford RJ, et al. 1998. Comparison of spontaneous and induced sputum for investigation of airway inflammation in chronic obstructive pulmonary disease. Thorax, 53:953-6. 
Bhowmik A, Seemungal TA, Sapsford RJ, et al. 2000. Relation of sputum inflammatory markers to symptoms and lung function changes in COPD exacerbations. Thorax, 55:114-20.

Biernacki WA, Kharitonov SA, Barnes PJ. 2003. Increased leukotriene B4 and 8-isoprostane in exhaled breath condensate of patients with exacerbations of COPD. Thorax, 58:294-8.

Bocchino V, Bertorelli G, Bertrand CP, et al. 2002. Eotaxin and CCR3 are up-regulated in exacerbations of chronic bronchitis. Allergy, 57:17-22.

Brightling CE, McKenna S, Hargadon B, et al. 2005. Sputum eosinophilia and the short term response to inhaled mometasone in chronic obstructive pulmonary disease. Thorax, 60:193-8.

Brightling CE, Monteiro W, Ward R, et al. 2000. Sputum eosinophilia and short-term response to prednisolone in chronic obstructive pulmonary disease: a randomised controlled trial. Lancet, 356:1480-5.

Brightling CE, Monterio W, Green RH, et al. 2001. Induced sputum and other outcome measures in chronic obstructive pulmonary disease: safety and repeatability. Respir Med, 95:999-1002.

Cao G, Booth SL, Sadowski JA, et al. 1998. Increases in human plasma antioxidant capacity after consumption of controlled diets high in fruit and vegetables. Am J Clin Nutr, 68:1081-7.

Celik P, Sakar A, Havlucu Y, et al. 2005. Short-term effects of montelukast in stable patients with moderate to severe COPD. Respir Med, 99:444-50.

Chapman JT, Otterbein LE, Elias JA, et al. 2001. Carbon monoxide attenuates aeroallergen-induced inflammation in mice. Am J Physiol Lung Cell Mol Physiol, 281:L209-L216.

Church DF, Pryor WA. 1985. Free-radical chemistry of cigarette smoke and its toxicological implications. Environ Health Perspect, 64:111-26.

Chvatchko Y, Proudfoot AE, Buser R, et al. 2003. Inhibition of airway inflammation by amino-terminally modified RANTES/CC chemokine ligand 5 analogues is not mediated through CCR3. J Immunol, 171:5498-506.

Coro ES, Chang WL, Baumgarth N. 2006. Type I IFN receptor signals directly stimulate local B cells early following influenza virus infection. J Immunol, 176:4343-51.

Davies L, Angus RM, Calverley PM. 1999. Oral corticosteroids in patients admitted to hospital with exacerbations of chronic obstructive pulmonary disease: a prospective randomised controlled trial. Lancet, 354:456-60.

de Jong JW, Belt-Gritter B, Koeter GH, et al. 1997. Peripheral blood lymphocyte cell subsets in subjects with chronic obstructive pulmonary disease: association with smoking, IgE and lung function. Respir Med, 91:67-76.

Di Stefano A, Capelli A, Lusuardi M, et al. 1998. Severity of airflow limitation is associated with severity of airway inflammation in smokers. Am J Respir Crit Care Med, 158:1277-85.

Donaldson GC, Seemungal TA, Bhowmik A, et al. 2002. Relationship between exacerbation frequency and lung function decline in chronic obstructive pulmonary disease. Thorax, 57:847-52.

Drost EM, Skwarski KM, Sauleda J, et al. 2005. Oxidative stress and airway inflammation in severe exacerbations of COPD. Thorax, 60:293-300.

Elsner J, Petering H, Hochstetter R, et al. 1997. The CC chemokine antagonist Met-RANTES inhibits eosinophil effector functions through the chemokine receptors CCR1 and CCR3. Eur J Immunol, 27:2892-8.

Fabbri LM, Hurd SS. 2003. Global strategy for the diagnosis, management and prevention of COPD: 2003 update. Eur Respir J, 22:1-2.

Fiorini G, Crespi S, Rinaldi M, et al. 2000. Serum ECP and MPO are increased during exacerbations of chronic bronchitis with airway obstruction. Biomed Pharmacother, 54:274-8.

Flood-Page P, Menzies-Gow A, Phipps S, et al. 2003. Anti-IL-5 treatment reduces deposition of ECM proteins in the bronchial subepithelial basement membrane of mild atopic asthmatics. $J$ Clin Invest, 112:1029-36.

Fujimoto K, Kubo K, Yamamoto H, et al. 1999. Eosinophilic inflammation in the airway is related to glucocorticoid reversibility in patients with pulmonary emphysema. Chest, 115:697-702.
Fujimoto K, Yasuo M, Urushibata K, et al. 2005. Airway inflammation during stable and acutely exacerbated chronic obstructive pulmonary disease. Eur Respir J, 25:640-6.

Furtmuller PG, Obinger C, Hsuanyu Y, et al. 2000. Mechanism of reaction of myeloperoxidase with hydrogen peroxide and chloride ion. Eur $J$ Biochem, 267:5858-64.

Gamble E, Grootendorst DC, Brightling CE, et al. 2003. Antiinflammatory effects of the phosphodiesterase-4 inhibitor cilomilast (Ariflo) in chronic obstructive pulmonary disease. Am J Respir Crit Care Med, 168:976-82.

Gerhard W, Mozdzanowska K, Furchner M, et al. 1997. Role of the B-cell response in recovery of mice from primary influenza virus infection. Immunol Rev, 159:95-103.

Gerritsen WB, Asin J, Zanen P, et al. 2005. Markers of inflammation and oxidative stress in exacerbated chronic obstructive pulmonary disease patients. Respir Med, 99:84-90.

Gilmour PS, Rahman I, Hayashi S, et al. 2001. Adenoviral E1A primes alveolar epithelial cells to PM(10)-induced transcription of interleukin8. Am J Physiol Lung Cell Mol Physiol, 281:L598-L606.

Gompertz S, O’Brien C, Bayley DL, et al. 2001. Changes in bronchial inflammation during acute exacerbations of chronic bronchitis. Eur Respir J, 17:1112-19.

Gosman MM, Willemse BW, Jansen DF, et al. 2006. Increased number of B-cells in bronchial biopsies in COPD. Eur Respir J, 27:60-4.

Gotfried MH. 2004. Macrolides for the treatment of chronic sinusitis, asthma, and COPD. Chest, 125(2 Suppl):52S-60S.

Heath H, Qin S, Rao P, et al. 1997. Chemokine receptor usage by human eosinophils. The importance of CCR3 demonstrated using an antagonistic monoclonal antibody. $J$ Clin Invest, 99:178-84.

Hersh CP, DeMeo DL, Lange C, et al. 2005. Attempted replication of reported chronic obstructive pulmonary disease candidate gene associations. Am J Respir Cell Mol Biol, 33:71-8.

Hewson CA, Jardine A, Edwards MR, et al. 2005. Toll-like receptor 3 is induced by and mediates antiviral activity against rhinovirus infection of human bronchial epithelial cells. J Virol, 79:12273-9.

Hogan RJ, Usherwood EJ, Zhong W, et al. 2001. Activated antigen-specific CD8+ T-cells persist in the lungs following recovery from respiratory virus infections. J Immunol, 166:1813-22.

Hogg JC, Chu F, Utokaparch S, et al. 2004. The nature of small-airway obstruction in chronic obstructive pulmonary disease. $N$ Engl $J$ Med, 350:2645-53.

Hou S, Doherty PC, Zijlstra M, et al. 1992. Delayed clearance of Sendai virus in mice lacking class I MHC-restricted CD8+ T-cells. J Immunol, 149:1319-25.

Hurst JR, Donaldson GC, Perea WR, et al. 2006a. Utility of plasma biomarkers at exacerbation of chronic obstructive pulmonary disease. Am J Respir Crit Care Med, 174:867-74.

Hurst JR, Perera WR, Wilkinson TM, et al. 2006b. Systemic and upper and lower airway inflammation at exacerbation of chronic obstructive pulmonary disease. Am J Respir Crit Care Med, 173:71-8.

Kerstjens HA, Timens W. 2003. Phosphodiesterase 4 inhibitors: antiinflammatory therapy for chronic obstructive pulmonary disease at last? Am J Respir Crit Care Med, 168:914-15.

Kitaguchi Y, Fujimoto K, Kubo K, et al. 2006. Characteristics of COPD phenotypes classified according to the findings of HRCT. Respir Med, $100: 1742-52$.

Kumar RK, Herbert C, Webb DC, et al. 2004. Effects of anticytokine therapy in a mouse model of chronic asthma. Am J Respir Crit Care Med, 170:1043-8.

Leckie MJ, ten Brinke A, Khan J, et al. 2000. Effects of an interleukin-5 blocking monoclonal antibody on eosinophils, airway hyper-responsiveness, and the late asthmatic response. Lancet, 356:2144-8.

Lee M, Goodbourn S. 2001. Signalling from the cell surface to the nucleus. Essays Biochem, 37:71-85.

Liang S, Mozdzanowska K, Palladino G, et al. 1994. Heterosubtypic immunity to influenza type A virus in mice. Effector mechanisms and their longevity. J Immunol, 152:1653-61. 
MacCallum PK. 2005. Markers of hemostasis and systemic inflammation in heart disease and atherosclerosis in smokers. Proc Am Thorac Soc, 2:34 43.

Madison JM, Irwin RS. 1998. Chronic obstructive pulmonary disease. Lancet, 352:467-73.

Majo J, Ghezzo H, Cosio MG. 2001. Lymphocyte population and apoptosis in the lungs of smokers and their relation to emphysema. Eur Respir J, 17:946-53.

Majori M, Corradi M, Caminati A, et al. 1999. Predominant TH1 cytokine pattern in peripheral blood from subjects with chronic obstructive pulmonary disease. J Allergy Clin Immunol, 103(3 Pt 1):458-62.

Maltais F, Ostinelli J, Bourbeau J, et al. 2002. Comparison of nebulized budesonide and oral prednisolone with placebo in the treatment of acute exacerbations of chronic obstructive pulmonary disease: a randomized controlled trial. Am J Respir Crit Care Med, 165:698-703.

Matsuse T, Hayashi S, Kuwano K, et al. 1992. Latent adenoviral infection in the pathogenesis of chronic airways obstruction. Am Rev Respir Dis, 146:177-84.

Mayr FB, Spiel A, Leitner J, et al. 2005. Effects of carbon monoxide inhalation during experimental endotoxemia in humans. Am J Respir Crit Care Med, 171:354-60.

McGuire A, Irwin DE, Fenn P, et al. 2001. The excess cost of acute exacerbations of chronic bronchitis in patients aged 45 and older in England and Wales. Value Health, 4:370-5.

Mercer PF, Shute JK, Bhowmik A, et al. 2005. MMP-9, TIMP-1 and inflammatory cells in sputum from COPD patients during exacerbation. Respir Res, 6:151.

Morrison D, Rahman I, Lannan S, et al. 1999. Epithelial permeability, inflammation, and oxidant stress in the air spaces of smokers. Am J Respir Crit Care Med, 159:473-9.

Niewoehner DE, Erbland ML, Deupree RH, et al. 1999. Effect of systemic glucocorticoids on exacerbations of chronic obstructive pulmonary disease. Department of Veterans Affairs Cooperative Study Group. N Engl J Med, 340:1941-7.

Ning W, Choi AM, Li C. 2005. Carbon monoxide inhibits IL-17-induced IL-6 production through the MAPK pathway in human pulmonary epithelial cells. Am J Physiol Lung Cell Mol Physiol, 289:L268-L273.

Noguera A, Busquets X, Sauleda J, et al. 1998. Expression of adhesion molecules and $\mathrm{G}$ proteins in circulating neutrophils in chronic obstructive pulmonary disease. Am J Respir Crit Care Med, 158(5 Pt 1):1664-8.

O'Shaughnessy TC, Ansari TW, Barnes NC, et al. 1997. Inflammation in bronchial biopsies of subjects with chronic bronchitis: inverse relationship of CD8+ T lymphocytes with FEV1. Am J Respir Crit Care Med, 155:852-7.

Otterbein LE, Bach FH, Alam J, et al. 2000. Carbon monoxide has antiinflammatory effects involving the mitogen- activated protein kinase pathway. Nat Med, 6:422-8.

Otterbein LE, Choi AM. 2000. Heme oxygenase: colors of defense against cellular stress. Am J Physiol Lung Cell Mol Physiol, 279: L1029-L1037.

Oudijk EJ, Gerritsen WB, Nijhuis EH, et al. 2006. Expression of primingassociated cellular markers on neutrophils during an exacerbation of COPD. Respir Med, 100:1791-9.

Papi A, Bellettato CM, Braccioni F, et al. 2006. Infections and airway inflammation in chronic obstructive pulmonary disease severe exacerbations. Am J Respir Crit Care Med, 173:1114-21.

Papi A, Romagnoli M, Baraldo S, et al. 2000. Partial reversibility of airflow limitation and increased exhaled $\mathrm{NO}$ and sputum eosinophilia in chronic obstructive pulmonary disease. Am J Respir Crit Care Med, 162:1773-7.

Parnham MJ, Culic O, Erakovic V, et al. 2005. Modulation of neutrophil and inflammation markers in chronic obstructive pulmonary disease by short-term azithromycin treatment. Eur J Pharmacol, 517(1-2):132-43.

Perera WR, Hurst JR, Wilkinson TM, et al. 2007. Inflammatory changes, recovery and recurrence at COPD exacerbation. Eur Respir J, 29:527-34.
Pizzichini E, Pizzichini MM, Gibson P, et al. 1998. Sputum eosinophilia predicts benefit from prednisone in smokers with chronic obstructive bronchitis. Am J Respir Crit Care Med, 158(5 Pt 1):1511-17.

Pizzichini E, Pizzichini MM, Leigh R, et al. 2002. Safety of sputum induction. Eur Respir J Suppl, 37:9s-18s.

Proudfoot AE, Buser R, Borlat F, et al. 1999. Amino-terminally modified RANTES analogues demonstrate differential effects on RANTES receptors. J Biol Chem, 274:32478-85.

Qiu Y, Zhu J, Bandi V, et al. 2003. Biopsy neutrophilia, neutrophil chemokine and receptor gene expression in severe exacerbations of chronic obstructive pulmonary disease. Am J Respir Crit Care Med, 168:968-75.

Rabe KF, Bateman ED, O'Donnell D, et al. 2005. Roflumilast - an oral anti-inflammatory treatment for chronic obstructive pulmonary disease: a randomised controlled trial. Lancet, 366:563-71.

Rahman I, MacNee W. 1998. Role of transcription factors in inflammatory lung diseases. Thorax, 53:601-12.

Rahman I, Skwarska E, MacNee W. 1997. Attenuation of oxidant/antioxidant imbalance during treatment of exacerbations of chronic obstructive pulmonary disease. Thorax, 52:565-8.

Record IR, Dreosti IE, McInerney JK. 2001. Changes in plasma antioxidant status following consumption of diets high or low in fruit and vegetables or following dietary supplementation with an antioxidant mixture. Br J Nutr, 85:459-64.

Rennard SI, Schachter N, Strek M, et al. 2006. Cilomilast for COPD: results of a 6-month, placebo-controlled study of a potent, selective inhibitor of phosphodiesterase 4. Chest, 129:56-66.

Retamales I, Elliott WM, Meshi B, et al. 2001. Amplification of inflammation in emphysema and its association with latent adenoviral infection. Am J Respir Crit Care Med, 164:469-73.

Ritter M, Mennerich D, Weith A, et al. 2005. Characterization of Toll-like receptors in primary lung epithelial cells: strong impact of the TLR3 ligand poly(I:C) on the regulation of Toll-like receptors, adaptor proteins and inflammatory response. J Inflamm (Lond), 2:16.

Rodriguez-Roisin R. 2000. Toward a consensus definition for COPD exacerbations. Chest, 117(5 Suppl 2):398S-401S.

Rohde G, Gevaert P, Holtappels G, et al. 2004. Soluble interleukin-5 receptor alpha is increased in acute exacerbation of chronic obstructive pulmonary disease. Int Arch Allergy Immunol, 135:54-61.

Roland M, Bhowmik A, Sapsford RJ, et al. 2001. Sputum and plasma endothelin-1 levels in exacerbations of chronic obstructive pulmonary disease. Thorax, 56:30-5.

Rothenbacher D, Brenner H, Hoffmeister A, et al. 2003. Relationship between infectious burden, systemic inflammatory response, and risk of stable coronary artery disease: role of confounding and reference group. Atherosclerosis, 170:339-45.

Rutgers SR, Timens W, Kaufmann HF, et al. 2000. Comparison of induced sputum with bronchial wash, bronchoalveolar lavage and bronchial biopsies in COPD. Eur Respir J, 15:109-15.

Rutten-van Molken MP, Postma MJ, Joore MA, et al. 1999. Current and future medical costs of asthma and chronic obstructive pulmonary disease in The Netherlands. Respir Med, 93:779-87.

Saetta M, Di Stefano A, Maestrelli P, et al. 1994. Airway eosinophilia in chronic bronchitis during exacerbations. Am J Respir Crit Care Med, 150(6 Pt 1):1646-52.

Saetta M, Turato G, Facchini FM, et al. 1997. Inflammatory cells in the bronchial glands of smokers with chronic bronchitis. Am J Respir Crit Care Med, 156:1633-9.

Seaton A, MacNee W, Donaldson K, et al. 1995. Particulate air pollution and acute health effects. Lancet, 345:176-8.

Seemungal TA, Donaldson GC, Paul EA, et al. 1998. Effect of exacerbation on quality of life in patients with chronic obstructive pulmonary disease. Am J Respir Crit Care Med, 157(5 Pt 1):1418-22.

Selby C, Drost E, Lannan S, et al. 1991. Neutrophil retention in the lungs of patients with chronic obstructive pulmonary disease. Am Rev Respir Dis, 143:1359-64. 
Sethi S, Maloney J, Grove L, et al. 2006. Airway inflammation and bronchial bacterial colonization in chronic obstructive pulmonary disease. Am J Respir Crit Care Med, 173:991-8.

Shindo K, Hirai Y, Fukumura M, et al. 1997. Plasma levels of leukotriene E4 during clinical course of chronic obstructive pulmonary disease. Prostaglandins Leukot Essent Fatty Acids, 56:213-17.

Shinkai M, Foster GH, Rubin BK. 2006. Macrolide antibiotics modulate ERK phosphorylation and IL- 8 and GM-CSF production by human bronchial epithelial cells. Am J Physiol Lung Cell Mol Physiol, 290: L75-L85.

Slebos DJ, Ryter SW, Choi AM. 2003. Heme oxygenase-1 and carbon monoxide in pulmonary medicine. Respir Res, 4:7.

Sunyer J, Saez M, Murillo C, et al. 1993. Air pollution and emergency room admissions for chronic obstructive pulmonary disease: a 5-year study. Am J Epidemiol, 137:701-5.

Tanaka H, Komai M, Nagao K, et al. 2004. Role of interleukin-5 and eosinophils in allergen-induced airway remodeling in mice. Am J Respir Cell Mol Biol, 31:62-8.

Teixeira MM, Wells TN, Lukacs NW, et al. 1997. Chemokine-induced eosinophil recruitment. Evidence of a role for endogenous eotaxin in an in vivo allergy model in mouse skin. J Clin Invest, 100:1657-66.

Thompson WH, Nielson CP, Carvalho P, et al. 1996. Controlled trial of oral prednisone in outpatients with acute COPD exacerbation. Am J Respir Crit Care Med, 154(2 Pt 1):407-12.

Tsoumakidou M, Tzanakis N, Chrysofakis G, et al. 2005a. Changes in sputum T-lymphocyte subpopulations at the onset of severe exacerbations of chronic obstructive pulmonary disease. Respir Med, 99:572-9.

Tsoumakidou M, Tzanakis N, Chrysofakis G, et al. 2005b. Nitrosative stress, heme oxygenase-1 expression and airway inflammation during severe exacerbations of COPD. Chest, 127:1911-18.

Tumkaya M, Atis S, Ozge C, et al. 2007. Relationship between airway colonization, inflammation and exacerbation frequency in COPD. Respir Med, 101:729-37.

Underwood DC, Osborn RR, Bochnowicz S, et al. 2000. SB 239063, a p38 MAPK inhibitor, reduces neutrophilia, inflammatory cytokines, MMP-9, and fibrosis in lung. Am J Physiol Lung Cell Mol Physiol, 279:L895-L902.

van der Strate BW, Postma DS, Brandsma CA, et al. 2006. Cigarette Smoke-induced Emphysema: A Role for the B Cell? Am J Respir Crit Care Med, 173:751-8. van der Vaart H, Koeter GH, Postma DS, et al. 2005. First study of infliximab treatment in patients with chronic obstructive pulmonary disease. Am J Respir Crit Care Med, 172:465-9.

Wedzicha JA, Seemungal TA, MacCallum PK, et al. 2000. Acute exacerbations of chronic obstructive pulmonary disease are accompanied by elevations of plasma fibrinogen and serum IL-6 levels. Thromb Haemost, 84:210-15.

Wetzler LM. 2003. The role of Toll-like receptor 2 in microbial disease and immunity. Vaccine, 21(Suppl 2):S55-S60.

White AJ, Gompertz S, Bayley DL, et al. 2003. Resolution of bronchial inflammation is related to bacterial eradication following treatment of exacerbations of chronic bronchitis. Thorax, 58:680-5.

White AJ, Gompertz S, Stockley RA. 2003. Chronic obstructive pulmonary disease . 6: The aetiology of exacerbations of chronic obstructive pulmonary disease. Thorax, 58:73-80.

Wilkinson TM, Hurst JR, Perera WR, et al. 2006. Effect of interactions between lower airway bacterial and rhinoviral infection in exacerbations of COPD. Chest, 129:317-24

Willemse BW, ten Hacken NH, Rutgers B, et al. 2005a. Effect of 1-year smoking cessation on airway inflammation in COPD and asymptomatic smokers. Eur Respir J, 26:835-45.

Willemse BW, ten Hacken NH, Rutgers B, et al. 2005b. Association of current smoking with airway inflammation in chronic obstructive pulmonary disease and asymptomatic smokers. Respir Res, 6:38.

Wood-Baker RR, Gibson PG, Hannay M, et al. 2005. Systemic corticosteroids for acute exacerbations of chronic obstructive pulmonary disease. Cochrane Database Syst Rev, 1:CD001288.

Woodland DL, Scott I. 2005. T cell memory in the lung airways. Proc Am Thorac Soc, 2:126-31.

Wouters EF. 2005. Local and systemic inflammation in chronic obstructive pulmonary disease. Proc Am Thorac Soc, 2:26-33.

Yamada N, Yamaya M, Okinaga S, et al. 2000. Microsatellite polymorphism in the heme oxygenase-1 gene promoter is associated with susceptibility to emphysema. Am J Hum Genet, 66:187-95.

Zagai U, Skold CM, Trulson A, et al. 2004. The effect of eosinophils on collagen gel contraction and implications for tissue remodelling. Clin Exp Immunol, 135:427-33.

Zhu J, Qiu YS, Majumdar S, et al. 2001. Exacerbations of Bronchitis: bronchial eosinophilia and gene expression for interleukin-4, interleukin-5, and eosinophil chemoattractants. Am J Respir Crit Care Med, 164:109-16. 
